
\title{
ZS Research Square \\ Scientists find new, rare mutations linked to inflammatory bowel disease
}

Shinichi Takahashi

Gaia Andreoletti

Rui Chen

Yoichi Munehira

Akshay Batra

Nadeem A. Afzal

R. Mark Beattie

Jonathan A. Bernstein

Sarah Ennis

Michael Snyder

Video Abstract

Keywords: Exome, Sequencing, Ulcerative colitis, Crohn's disease

Posted Date: March 12th, 2021

DOI: https://doi.org/10.21203/rs.3.rs-319005/v1

License: (1) This work is licensed under a Creative Commons Attribution 4.0 International License.

Read Full License 


\section{Abstract}

A team at Stanford and Southampton Universities has discovered a new set of mutations that could explain why certain people have inflammatory bowel disease, or IBD. While the mutations are rare, they point to an important role for a family of so-called chaperone proteins, which help other proteins fold properly in cells, and offer new ways to treat the disease. IBD is an autoimmune disease characterized by inflammation of the gastrointestinal tract, and comes in two common forms: Crohn's disease and ulcerative colitis. Patients usually suffer from abdominal pain and diarrhea. In severe cases, people can't absorb enough nutrients, and the condition becomes life-threatening. While environmental factors play a role, so do genes. Scientists have identified more than 160 positions in the genome where variants can increase the risk of developing the disease. But they still explain just a fraction of the genetic contribution. To identify mutations that might be less common, but more important in driving the condition, the researchers turned to one 16-year-old girl with ulcerative colitis. She had no family history of IBD, so the team sequenced her exome - or all of her genes coding for proteins - along with those of her parents and brother, looking for critical differences. They found the girl had a mutation in a critical part of a gene that codes for a heat shock protein, a type of chaperone. To see if other IBD patients had similar defects, the geneticists checked nearly 140 other sick children in the UK, and found five other variants within the same heat shock protein. When the team tested the effect of these mutations on protein function in the lab, they found that the mutant chaperones lost much, if not all, of their ability to fold proteins. The results are the first to associate IBD with this particular heat shock gene, and suggest it may be worth testing for mutations to better evaluate IBD risk. Future work may also reveal a targeted way to treat those with this particular version of the disease. 